\title{
Crisis, what crisis? A feminist analysis of discourse on masculinities and suicide
}

\author{
Ana Jordan, University of Lincoln \\ Amy Chandler, University of Edinburgh
}

\begin{abstract}
High male suicide rates are often constructed as evidence for an apparent "crisis of masculinity". Conversely, "crisis of masculinity" has been used to explain differential rates of male and female suicide in the UK (and elsewhere). We analyse three public cases where male suicide and "masculinity-crisis" discourse are employed together. Our feminist analysis demonstrates that "crisis talk" and male suicide are addressed in divergent ways. We therefore distinguish between "progressive" and "conservative" crisis narratives. Conservative narratives position high male suicide rates as a pernicious outcome of "threats" to traditional gender roles and norms, suggesting the solution is to return to them.

Contrastingly, progressive crisis accounts use male suicide to demonstrate that existing gender norms harm men as well as women and argue they should be altered to address male suicide. Conservative narratives often map on to anti-feminist politics, whereas progressive accounts reflect aspects of feminism. There is no neat feminist/anti-feminist distinction, however, as postfeminist ideas are also evident. We argue that, overall, each of the articulations of a "crisis of masculinity" as evidenced by high rates of male suicide reinforces problematic gender politics. Further, in reifying simplistic, dualistic models of gender, they may ultimately constrain efforts to reduce suicide.
\end{abstract}

KEYWORDS: suicide, crisis, masculinities, men's health, men's movements 


\section{Introduction}

A gap between male and female suicide rates has been a longstanding feature of knowledge about suicide (Durkheim, 1952; Jaworski, 2014; Scourfield, 2005). In the majority of countries where data is available, rates are between three and five times higher among men than women (Payne, Swami, \& Stanistreet, 2008). For instance, the latest UK rates are 3.1 times higher for men than women; though this difference varies across time, region and age group (Scowcroft, 2017). Recently in the UK the difference between male and female suicide rates has been greatest among those in mid-life, aged between 35 and 54 (Wyllie et al., 2012). This is undoubtedly a worrying picture. There is scepticism, however, that such statistics reflect the "reality" of suicide as they incorporate gendered assumptions about what counts as suicide, ignoring higher rates of attempted suicide (as opposed to completed suicide) and selfharm among women (Jaworski, 2014; Scourfield, 2005). Commentaries on men's health frame suicide as one among many health inequalities faced by men, including lower life expectancies, specific forms of cancer, and heart disease (Courtenay, 2000; Creighton \& Oliffe, 2010). High (and sometimes rising) rates of male suicide have been constructed as one among many pieces of evidence that men, and masculinity, is in "crisis" (Canetto \& Cleary, 2012; Scourfield, 2005). It is the gender politics of these deployments of male suicide which we seek to analyse/trouble in this article.

The "problem" of male suicide has recently received heightened attention in UK public discourse, driven by: interventions from high-profile media commentators and celebrities (e.g. musician Professor Green, comedian and author Stephen Fry); coverage of deaths of well-known men who have died by suicide (e.g. footballer Gary Speed, actor Robin Williams); and the activities of suicide prevention charities (e.g. the Samaritans' 2012 Men, Suicide and Society report). Researchers across different disciplines have also begun to address male suicide as a gendered issue, though as Katrina Jaworski (2014) and others have 
noted, research investigating male suicide often lacks a critical gender perspective (Canetto, 2017; Mac an Ghaill \& Haywood, 2012; Mallon, Galway, Hughes, Rondón-Sulbarán, \& Leavey, 2016; Scourfield, 2005). In this article, we contribute to ongoing efforts to subject the "problem" of male suicide to critical analysis. In doing so, we align ourselves with Jaworski's arguments for a more nuanced and critical analysis of the 'gender of suicide'. Like Jaworski, we are concerned with how suicide itself, as well as discourse about suicide, comes to be gendered, in addition to examining how understandings of suicide contribute to broader gender discourses. This argument also supports Connell's (2012, p. 1675) call for 'gender [to be] seen as the active social process that brings ... bodies into history, generating health consequences not as a side-effect but in the making of gender itself'.

Our arguments draw on an analysis of public discourse about suicide, based on three UK case studies where public figures have employed the notion of "crisis" to articulate a close relationship between gender and suicide. The texts are written/spoken by: Labour party MP Diane Abbott, activist Glen Poole, and Jane Powell, former CEO of men's suicide prevention charity, the Campaign Against Living Miserably, or 'CALM.' ${ }^{1}$ These cases are examples of a broader trend where high male suicide rates are constructed in various contexts as the starkest outcome of "masculinity in crisis". Our analysis demonstrates that this discourse is framed in divergent ways, with differing relationships to feminist thought. We term these conservative and progressive crisis narratives. However, we suggest that in both conservative and progressive perspectives, discourse about suicide among men draws upon simplistic and dualistic models of gender, obfuscating complexity and diverting attention from the existence and potentialities of multiple masculinities/femininities. Ultimately, we argue, such discourse

\footnotetext{
${ }^{1}$ CALM - Campaign Against Living Miserably, Jane Powell is a co-founder of the charity which campaigns to reduce male suicide, and was CEO from its inception in 2005 up until 2017 when she stepped down.
} 
may constrain attempts to better understand (and reduce) rates of suicide among men and women.

\section{Crisis of masculinity?}

In the UK, played out in the media, in politics, and in popular culture, talk about a "crisis" of masculinity has expanded (Roberts, 2014). Numerous issues have been constructed as symptomatic of a crisis of masculinity, for example, men's criminality, boys' schooling, working-class men's employment opportunities, "absent" fatherhood and the "breakdown" of the family (Griffin, 2000; Jordan, 2014; McDowell, 2000). High rates of male suicide are frequently employed as a piece of especially compelling evidence of this purported crisis (Scourfield, 2005).

Both the idea and actuality of a "crisis of masculinity" has been thoroughly critiqued by gender scholars. Connell (2005b, p. 84) has suggested that the entire 'gender order' has 'crisis tendencies' as masculinity is not a stable signifier. There are contradictions internal to masculinity, and to the gender order, which render both inherently unstable. It is therefore perhaps unsurprising that masculinity might be construed as almost continually under threat. Whilst these threats are partially imaginary, the result of the contingent, fragile social construction of masculinity, "crisis" discourse becomes most intense at times of rapid social, economic and political change, or when social movements challenge inequality, injustice and oppression (de Boise, 2014; Kimmel, 2013; Roberts, 2014; Whitehead, 2002). Masculinity panics have been documented in different locations at various points across the last four centuries (Kimmel 2012; Whitehead 2002), and at least as far back as the French Revolution (Lampron, 2008 in Blais \& Dupuis-Déri, 2012, p. 24). In short, 'concerns about men [...] were never far from social and political discourse' (Whitehead 2002: 58). 
Crises of masculinity continue to emerge as a matter of concern in popular and public discourse about men. These periodic crises are often presented as distinctly modern and novel, a move driven by efforts to mobilise nostalgia about a mythical, romanticised past when men were "real" men (invariably white, heterosexual) and women were "proper women" (Kimmel 2012; Whitehead 2002). While there are common themes across "crisis" narratives, there are also disjunctures in the framing of gender and gender relations. We therefore distinguish between what we call conservative and progressive crisis narratives. Conservative crisis narratives construct high rates of male suicide as a particularly serious outcome of ongoing threats to "traditional" gender roles and norms and advocate returning to them. In contrast, progressive accounts draw on crisis narratives, but use male suicide to demonstrate that existing gender norms harm men as well as women, arguing that to address male suicide, they should be altered. The conservative/progressive distinction is understood as an analytical tool rather than a rigid distinction, and the case studies do not necessarily fall neatly into one category. The distinction is used to highlight and emphasise the point that while approaches which seek to alter masculinity may appear more radical, they are also limited. Despite resonances across history and different political, cultural and socioeconomic settings, the cases we analyse are to some extent specific to their contemporary UK context and are also a small sample of the available texts within that context. The analytical framework is therefore not presented as a universally applicable, generalisable typology, but as an illustrative, theoretical device.

\section{Gender, suicide and self-harm}

Emile Durkheim's (Durkheim, 1952) Le Suicide notoriously dismissed female suicide because it was apparently so uncommon. Durkheim's thesis regarding suicide emphasised the importance of social bonds in understanding why suicide rates changed over time. Women, he argued, were naturally less socially involved, and therefore less vulnerable to suicide due 
to damaged social bonds. Perhaps related to this early portrayal of female suicide as largely irrelevant, most suicide research has proceeded to assume a non-gendered, but nevertheless implicitly male (and usually white, heterosexual) subject.

In contrast, our own approach to gender and suicide is informed by critical gender theories which seek to unsettle binary, biologically determinist distinctions between men and women, emphasising instead the socially and culturally contingent nature of gender (Connell 2005b). Within suicide research, this approach is well illustrated in Jaworski's $(2003,2014)$ compelling deconstructions of gender and suicide. Jaworski argues that the gendering of suicide is intimately related to the nature of suicidology, with pre-existing constructions of gender infusing understandings of what suicide is in the field. Drawing on Judith Butler's theory of performativity, Jaworski argues that suicide can be understood as process of "ritualized [repeated] bodily gestures that speak of gender" (2014, p. 42). Gender may implicitly shape average differences in how men and women suicide, via 'choice' of particular suicide methods. Further, on a broader symbolic level, gendered assumptions also fundamentally shape how acts of suicide - or self-harm - are interpreted. Jaworksi's arguments resonate with, and add a distinct gendered dimension to, that of other critical scholars of suicide (particularly, though not exclusively, those working in the humanities and social sciences) who have demonstrated the multiple ways in which practices and knowledge about suicide (and self-harm) are contingent, performative, and contested (Chandler, 2016; Douglas, 1967; Marsh, 2010; Timmermans, 2005).

As Jaworski notes, one of the ways in which suicide research has been shown to rely intimately on gendered understandings is in the demarcation of suicide from self-harm. Selfharm is associated with women, more likely framed as 'passive', 'attention-seeking', a 'failed attempt'. For Jaworski, such framing enables suicide to be constructed as 'active', 'successful' - traits commonly represented as masculine. She argues that these characteristics 
are not inherent aspects of acts of self-harm (whether these result in death or not), but are read into them, through gender. The frequent, repetitive, emphasis on the divergence between male and female suicide rates is part of this gendering, and can deflect attention from the higher rates of non-fatal self-harm, including 'attempted suicide', that are reported/recorded among women (Canetto \& Sakinofsky, 1998). Instead, discourse about suicide often focuses almost exclusively upon suicide as a problem for men (Canetto \& Cleary, 2012; Mallon et al. 2016; Oliffe et al., 2017; Scourfield, Fincham, Langer, \& Shiner, 2012). The 'gender paradox' in suicide and self-harm has been identified for at least 20 years, and has been considered in some attempts to understand higher rates of men's suicide compared to women. Hypotheses include: men use more fatal methods when self-harming, increasing chances of death, while women are more likely to live; men being less likely to seek help for mental health problems; and suggestions that part of the paradox results from biased data/reporting (Canetto \& Sakinofsky, 1998; Payne et al., 2008).

Our analysis contributes to critical studies of suicide (a 'critical suicidology', see White, Marsh, Kral, \& Morris, 2016) in demonstrating how suicide is enrolled as a "fact" to support arguments about a "crisis" of masculinity. By interrogating the politics of masculinities at work in the case studies, we support claims about the problematic construction of suicide in masculinist terms.

\section{Accounts of suicide, crisis and men}

To illustrate the divergent ways that crisis of masculinity narratives are articulated in public accounts of male suicide, we analyse three non-academic textual case studies centred around UK public figures who have been vocal on this issue. Consonant with our in-depth, qualitative approach in this paper, the cases were chosen to reflect and illustrate our primarily theoretical concerns with the contemporary politics of gender and male suicide as they reflect 
different elements of progressive and conservative versions of crisis of masculinity discourse that draws upon male suicide. These are not, of course, the only examples where "crisis" narratives invoke male suicide, nor are they fully representative of such discourse. However, they do resonate with other articulations of links between male suicide and crisis (Scourfield 2005), as well as with wider crisis of masculinity narratives identified in the literature. These specific cases were selected as opposed to others which might have fulfilled the theoretical criteria, because they have each been prominent in recent UK public discourses, and they "speak" directly to each other, as outlined below. Finally, the cases arise from slightly different contexts/perspectives which are influential in terms of understanding gender and suicide - the formal political arena, men's activism, and a suicide prevention campaign. As discussed in the conclusion, we recognise that cases articulated within other arenas and from alternative perspectives could be equally illuminating, and we hope that future research will build on the insights derived from this small, exploratory study.

The first case is a transcript of a speech given in 2013 by Labour party Member of Parliament (MP), Diane Abbott. Abbott's speech is selected as an exemplar of a predominantly progressive narrative about the purported crisis of masculinity in contemporary Britain. The second case is writing by Glen Poole, a commentator and activist on 'men's issues'. We examine Poole's response to a pre-released summary of Abbott's speech, published in The Guardian in 2013. This is supplemented with some of Poole's more recent writing addressing masculinity, crisis and suicide. In contrast to Abbott, we argue that Poole's perspective is broadly paradigmatic of a conservative, anti-feminist, crisis narrative. Our third case consists of articles and blogs by Jane Powell, founder and former CEO of a men's suicide prevention charity, CALM. There are interesting links between Powell and Poole, as Poole has contributed to CALM's website, and served on the advisory board for the 2014 Crisis of Male Suicide report commissioned by CALM, which we discuss below. 
Our primary aim in deconstructing these texts is not to interrogate the factual accuracy of the claims made about men and suicide. Instead, our intention is to use them as a heuristic device, indicative of the terms in which public discussion of male suicide, and the "crisis" of masculinity is currently taking place in contemporary Britain. This reflects a feminist 'displacement' approach which entails challenging 'the hold of particular gendered discourses' (Squires, 1999, p. 111). This branch of feminist analysis takes narratives/texts seriously, drawing attention to their power-laden effects, and seeking to both reveal and disrupt the socially constructed assumptions underpinning dominant ideas of gender (in this case in relation to suicide).

The textual analysis was conducted thematically. Both authors independently read the texts and investigated questions such as: how is masculinity constructed?; how is masculinity linked to male suicide?; how is gender perceived (socially/biologically determined)?; is "crisis" conceived of as positive or negative?; is feminism invoked as related to male suicide and if so, how?; what solution(s), if any, are proposed to deal with a) male suicide and b) crisis of masculinity more generally; what is highlighted and/or obscured about gender and suicide? Overall, we critically interrogated the gendering of suicide in these accounts, with final themes arrived at and agreed through a process of iterative discussion and deliberation. While we identified many commonalities across these texts in their response to, and construction of, the "problem" of male suicide and masculinity, our analysis drew out important differences, suggesting the very different orientations each writer/speaker has to feminism.

\section{Diane Abbott: Britain's crisis of masculinity}

In 2013, Diane Abbott, Labour MP for the constituency of Hackney North and Stoke Newington, gave a speech entitled 'Britain's Crisis of Masculinity' (Abbott 2013). Of the 
three cases analysed in this paper, Abbott's speech engages least explicitly with the "problem" of male suicide. Suicide is mentioned briefly, as one of many social ills which Abbott (2013, p. 2) associates with 'a crisis that for too long has been unspoken':

This year, too many British men will return home so late, that happy family life will be pushed even further out of reach; too many British men will be diagnosed with a cancer that was preventable; $[\ldots]$ too many British men - shouldering the burden of a growing economic mess they did not create - will commit suicide (p. 3)

Abbott's speech portrays these challenges as resulting from rapid social change which has impacted negatively on men, creating disadvantages that are simply not acknowledged or tackled by an indifferent society. This theme, of men or masculinity in crisis being unrecognised, is common across the case studies.

Abbott (p. 2), however, emphasises her credentials as a 'card-carrying feminist'. She criticises those who blame women for society's ills, and notes that women are still lacking equality in many respects (p. 8). Consonant with a progressive crisis of masculinity narrative, she explicitly dismisses essentialist views of gender: 'narrow stereotypes, based upon biological differences, have finally been laid to rest' (p. 7). Abbott (p. 4) highlights some of the damaging aspects of traditional masculinity, 'the masculine predilection for risk and violence' for both men and women, saying that she is 'particularly troubled by a culture of hyper-masculinity', characterised as misogynistic, homophobic, and racist.

At the same time, however, Abbott charts the purported contemporary nature of this crisis by creating an evocative picture of a sepia-tinted vision of how men used to be:

Thinking about old expressions of masculinity is like flicking through a dusty, wellworn, black and white photo album from a loft - the men who toiled in the iron, steel and coal industries, in shipbuilding, and pre-mechanised farming. The soldier, the 
bank manager, the breadwinner, the family man. Yesterday's heroes, in the fantasies and the realities of British life, were affirmed, in part, by physical strength, silent stoicism, and athletic daring (p. 4)

The problem facing men today is that the 'gold standard' of 'what made a British man' has 'melted into taking, owning and consuming' (p. 6). Men are constrained by an idealised masculinity, now unattainable due to changing social and economic contexts: the decline of heavy industry, and rise of consumerism. Whilst Abbott's progressive take on crisis envisages altering masculinity to allow men/boys to adapt to a changed world, there is a clear sense of longing for the industrial past when men could be "real" men. Romanticised notions of men's roles in a fictional past surface when crisis of masculinity narratives become prominent (Kimmel 2012). As discussed below, what we call conservative crisis perspectives rely even more heavily on mournful lamentations about times gone by and fail to recognise negative aspects of traditional styles of masculinity. Nevertheless, such fantasies of simpler masculinity-times, albeit tempered in more progressive accounts like Abbott's, are often a key feature of even the most promising understandings of the apparent crisis of masculinity. Unlike more conservative commentators, Abbott does not suggest we return to this mythologised past. The varied solutions she proposes include practical/policy changes including provision of work and better vocational/technical education opportunities for (working-class) men and men-specific helplines for mental health issues (p. 13). Abbott also emphasises the need for cultural change in the social constructions of gender which lead to men's problems in the arenas she identifies as locations of "crisis". For example, health campaigns targeted at men should highlight that 'needing health treatment isn't a mark of failure' and, in education, 'we must challenge male gender identities which do not value learning and reading as a mark of success' (p. 10). More generally, 'we' need to: 
establish and normalise a multi-faceted notion of what makes a man - in our schools, families and workplace - which allows and encourages sensitivity, emotions, healthy sexuality, communication, and investing time in children $[\mathrm{sic}]$ education (p. 10)

Abbott (p. 10) emphasises that the solution of promoting different forms of masculinity is not 'about turning boys into girls. It's about making boys feel like they can talk about their place in the world'. Thus, while Abbott's overall approach to the 'crisis' of masculinity seeks to alter dominant masculinity, there remains a restrictive commitment to binary gender in terms of maintaining the difference between "boys and girls".

Abbott's version of "masculinity crisis" invokes male suicide only briefly, as part of a broader argument about the challenges facing men, especially younger, poorer men, in Britain. However, high male suicide rates are framed as a key example illustrating the starkest outcome of a society where masculine identities have not "caught up" with changing social contexts. Interestingly, Abbott's arguments are partly in keeping with some scholarship around gender and suicide (Cleary, 2012) and indeed about masculinity in general (McDowell, 2000). Nonetheless, positioning suicide as being about "men in crisis", even in Abbott's purportedly feminist account, exaggerates male distress and trivialises women's, obscuring the ways in which the costs of masculinity are a result of its benefits (Connell, 2005a). Women's inequality and the costs of masculinity for women are diminished.

\section{Glen Poole: Machismo and the male suicide emergency}

Glen Poole's work exemplifies a conservative crisis narrative. Poole is a writer and selfidentified 'men's issues' activist. Our analysis primarily examines two comment pieces, published in The Guardian (2013), and The Telegraph (2015), two British broadsheet newspapers which speak politically to the left and right respectively. Poole's 2013 Guardian article responded to a pre-released transcript of Abbott's speech analysed above. The 
Telegraph article commented on a speech by Labour MP (now party leader) Jeremy Corbyn addressing the 'public health emergency' of male suicide. Ostensibly, Abbott and Poole discuss the same "crisis", and enrol suicide similarly. However, there are significant differences in how they frame the problem and cause(s) of male suicide.

While Poole and Abbott (and Corbyn) agree there is a problem for men, and that this is evidenced by male suicide rates; they disagree over why men die by suicide in higher numbers. Consequently, they disagree over proposed solutions. In the two comment pieces (and his other writing), Poole strongly rebuts critiques of masculinity as itself a factor causing male suicide. In the 2013 piece, Poole's (2013) tone is caustic: 'masculinity is in crisis again and this time the Labour party is going to save us'. He criticises Abbott's apparent demonisation of men and masculinity:

a familiar, negative narrative about disaffected men who are hyper-masculine, homophobic, misogynistic [...] Abbott is right to say that there aren't enough men engaged in conversations about manhood, but is it any wonder when modern masculinity is described in such negative terms? (Poole 2013)

Poole suggests that men are not "really" so bad as Abbott makes out and, that, like other feminists, she condemns men and "manhood", shutting down potential conversations. Rather than masculinity being the problem, Poole argues that it is feminism that constrains attempts to tackle 'men's issues'. He critiques Abbott (and feminism) for suggesting that: 'women have problems and men are problems' (Poole, 2013). Dealing with men's issues means challenging 'the dominance of feminist thinking in the gender equality sector' (Poole, 2013). For Poole (2015):

when it comes to gender politics it's constantly raining women, leaving men without a lifebelt, caught between the rocks of the traditional, socially conservative desire to 
protect women and children and the hard place that is the progressive, socially liberal drive to champion women and girls

Poole's perceptions of apparent feminist bias in politics resonate with wider 'backlash' narratives (Faludi, 1991) - feminism has gone too far and unfairly privileges women; feminism is an obstacle to gender equality; feminism undermines the natural gender order, thereby causing social harm (suicide).

Poole's 2015 response to Corbyn more explicitly defends "traditional masculinity". Like Abbott, Corbyn suggested that high male suicide rates are tied to outdated masculine ways of being - especially the idea that men should be strong and silent, not communicating about, or seeking help for, problems. Poole (2015), in contrast, argues that Corbyn's 'soundbite theory that "macho culture" is the problem and "speaking out" is the cure, doesn't stand scrutiny':

There is plenty of evidence to suggest that for some men, being a straightforward, ordinary bloke is a perfectly good defence against suicide. Being able to take on the provider and protector role, with a wife and kids, gives these men the security and responsibility of having a family to look out for [...] These men may be part of the "macho culture" that Jeremy Corbyn dislikes, but their "keep calm and carry on" approach to manhood works for them and we should honour and respect that

Poole enrols male suicide rates to defend "traditional" masculinity, ignoring the implications for women's equality of reinforcing protector/provider roles. This is also problematic as men's suicide rates have always been higher than women's, even when these roles were easier for men to access. Poole's framing conflicts with recent analysis that indicates greater gender equality is not associated with rises in male (or female) suicides; indeed, gender equality appears to be protective for men during economic upheavals (Reeves and Stuckler, 2016). 
Poole (unlike Abbott) opposes both softening masculinity, and any recognition of masculinity as socially constructed rather than natural/biological. He claims it is men being prevented from fulfilling natural masculine roles and the censoring of provider/protector masculinity which is problematic: 'it's not a "macho culture" that prevents men from "speaking out"; it's a culture that isn't yet "man enough" to listen and respond to men's needs' (Poole, 2015). Masculinity is singular, inevitable, and constructed in opposition to femininity. Men should not be expected to be "like women".

More recently, Poole has suggested ways to reduce male suicide, drawing on his conservative framing of masculinity in crisis, which views men as discriminated against in mental health and suicide prevention efforts. One of his suggestions is to 'Stop Victim Blaming' men: 'we need to stop blaming men for not getting help, and start asking ourselves how we can all get better at helping men' (Poole 2016). Better provision of 'male-friendly' services is echoed by Abbott. However, again, the two diverge regarding masculinity: while Abbott argues we also need to support men to embrace alternative masculinities, Poole (2015) sees masculinity as biological/natural, and as such something inevitable to honour and respect.

Poole's account of masculinity - contra Abbott - frames gender in essentialist terms. While both Abbott and Poole highlight the impact of changing employment markets, especially the decline of heavy industry, as contributing to the problems that men face; there are important differences in how this is understood. Both romanticise a past where men had jobs which allowed them to express a particular masculinity: strong, physical, accomplished, and earning enough to maintain a family as sole breadwinner. Abbott, however, believes what is prized about "being a man" can and should change to adapt to modern society and avoid the damaging effects of traditional masculinity on men (and women). Poole, instead, argues men cannot and should not have to change, traditional masculinity is damaging only when men are prevented from "being men"and are thereby led to suicide. It is society (and especially the 
purported dominance of feminism) which must be altered. This indicates a much more fixed, conservative understanding of masculinity, and of the apparent "crisis of masculinity" being narrated.

To summarise, Poole's account of the problem of male suicide, and "crisis" of masculinity diverges from Abbott's in perceptions of how fixed masculinity is, and of the drivers of the "crisis". While for Abbott, the causes are changing economic contexts, and to some extent problems internal to masculinity itself; for Poole the causes are all external to masculinity changing economic structures, but also - importantly - the impact of women's movements, and feminism. In Poole's account, it is the alleged privileging of women's issues over men's which causes/exacerbates the "crisis" facing men, and - implicitly - contributing to the higher numbers of men who die by suicide as compared to women.

The "men versus women" framing impedes more complex engagement with the role of masculinity in male suicide. The simplistic focus on binary gender and the understanding of masculinity (and femininity) as singular and homogenised, also side-lines issues of power located in complex social structures. The cases largely position gender as isolated from other intersectional inequalities regarding race, class, or sexuality, which, in conjunction with gender, are shown to contribute significantly to suicide and self-harm specifically (McDermott \& Roen, 2016), and distress more widely (Mirowsky \& Ross, 2003)

\section{Jane Powell: Suicide as a crisis of modern masculinity}

In our final case, we draw on three examples of writing by Jane Powell, former CEO of male suicide prevention charity CALM. Powell's case sits between Abbott and Poole, incorporating a broadly progressive form of crisis narrative, but one inflected with strands of conservatism. Further, Powell's writing implies a postfeminist orientation, which is not as prominent in Abbott or Poole's writing, resulting in an additional, distinctive iteration of the use of suicide 
as part of a "crisis" of masculinity narrative. Powell's distinct employment of the notion of crisis, further underlines the problematic nature of drawing on such narratives to "tackle" the problem of male suicide; as well as the problematics inherent in "tackling" male suicide without falling foul of essentialist, unproductive, and unhelpful notions of gender identity and gender relations.

CALM's report, A Crisis in Modern Masculinity: Understanding the causes of male suicide explicitly situates male suicide as resulting from 'crisis' (Welford \& Powell, 2014). A piece publicising the report on CALM's website articulates themes which we have argued are central to crisis narratives:

The role of men is being transformed by globalised forces from economics to technology to feminism. And men are faring particularly badly in many areas of life. From homelessness to education, alcohol and drug misuse to general life expectancy, they are clearly finding it increasingly difficult to cope as they try to adapt to circumstances that are entirely unprecedented (CALM, 2014, our emphasis)

The purported novelty of disruptions to masculinity is emphasised and men are situated as disproportionately impacted by societal change caused by, inter alia, feminism and global economic structures. The report explores whether men and women experience expectations and pressures differently. Overall, it is argued: 'men often feel negatively stereotyped by the media, feel too much is expected of them, and do not feel that their needs are being considered by employers' and that 'considering the higher suicide rate across all ages for men than women, the UK in 2014 isn't quite a "Man's World”; thousands of men and boys each year find themselves unable any longer to live in it' (Welford and Powell 2014, p. 33). Men are positioned here as the new gender victims. There is an implicit critique of assumptions 
that gender inequality is predominantly experienced by women, with higher male suicide rates posited as an unquestionable piece of evidence supporting this view.

A postfeminist understanding is also present in the situating of feminism as in the past, having now achieved its aims for women (McRobbie, 2009): 'women have clearly benefitted from the cultural changes of the last few decades. It's now time for men to find their own language of change, and for society and government to [...] respond to, suicide as a gender issue' (Welford and Powell 2014, p. 3). The claim is not that women have gained at the expense of men as anti-feminist perspectives would suggest (Faludi, 1991), but that women's problems have now largely been solved and it is time to move on to the unacknowledged, but equally problematic, gendered issues facing men.

Like Poole, Powell's writing often refers to the apparent lack of attention paid to the problem of male suicide. These claims situate Powell more in line with conservative, anti-feminist crisis discourses, reflecting "men's rights" discourses that men are marginalised (Jordan, 2016; Messner, 2000):

Is it more about society? Is at least in part biology? Are there environmental factors, such as testosterone reducing drugs, which might explain at least some of this? The problem isn't just that we don't know. The problem is that we're not even asking the question (Powell, 2016, our emphasis).

Powell suggests assumptions about male suicide are based on 'lazy truisms' that 'men drink more, visit the doctor less, and take more fatal methods [...] poverty, divorce, being a breadwinner are good thoughts. But women face the same issues. So why men?' (Powell 2016, our emphasis). This is an intriguing standpoint. As discussed above, there is a growing body of research on gender/sex differences in suicide (Andriolo, 1998; Canetto, 1991; Canetto \& Cleary, 2012; Möller-Leimkühler, 2003). It is therefore simply not true (contra 
Powell) to say that no-one is asking questions related to the problem of 'why men'?

However, scholars have argued that these questions are frequently not asked in productive ways because they are based on preconceived, unreconstructed myths about the "nature" of men and women (see Canetto \& Cleary, 2012; Hill \& Needham, 2013; Jaworski, 2014). Further, as Powell (2016) points out, this is not particularly helpful in terms of explaining and preventing suicide: "we know the expectation that "real men should be strong, silent and in control" is a huge barrier to men seeking help' but ' just telling men to get help doesn't in itself take us very far. How do we actually prevent male suicide and what is driving these suicides?'

Elsewhere, Powell (2014) suggests that men's issues are ignored because 'male' is a 'dirty word' and gender equality is perceived as only pertaining to women. Men's issues are represented as invisible and devalued, even taboo. This claim, again, resonates with a postfeminist construction of crisis which frames women's equality as achieved. Given the arguments presented above regarding the cyclical, vociferous proclamations about masculinity/men in crisis across history, the notion that men as a category are invisible is problematic.

Powell is partly correct in saying that men are often not perceived of as marked by gender and that gender is seen as synonymous with women (Carver, 1996). However, her analysis misses that it is this invisibility of men as a gender category which enables their overall privilege. To the extent that gender is not always interrogated in relation to men, this is not the result of men's oppression, but precisely because masculinity and men's power is taken for granted (Connell, 2005b). Critical suicidologists have highlighted how the broader positioning of men as generically "human" has fed into the underestimation of suicide by women and constructions of attempted suicide as "less serious" than completed suicide (Jaworski, 2014; Mallon et al., 2016). 
In different ways, each of the cases analysed emphasises that men "have problems" and that focusing on men "as a problem" detracts attention from men's problems. Each also

simultaneously enrols high rates of male suicide as "proof" of masculinity in crisis, ultimately contributing to the reification of the idea of a "male suicide problem". Through this indirect/inadvertent rearticulation of suicide as inherently male or masculine, male suicide is naturalised. This is especially problematic in the conservative aspects of the cases, which reassert both links between masculinity and suicide, and problematic notions of masculinity as biologically determined.

\section{Conclusion: Suicide in crisis?}

Problems with interpreting male suicide through a "crisis" lens have previously been highlighted as crisis theories of male suicide are 'based on limited empirical data, ignore [...] significant variations in suicidal behaviour [...] and deal [...] with gender in a simplistic way' (Canetto and Cleary 2012, p. 462). Our analysis furthers this assessment, demonstrating how crisis narratives emerge in public accounts, and the work that they do in constructing both suicide, and masculinity. Crucially, we show how these accounts are situated regarding gender politics in important, but divergent, ways. Indeed, we would argue that to fully understand current articulations of crisis, suicide and gender, we must engage with contemporary gender politics. Our analysis demonstrates the ways in which research about gender and suicide is politicised, with suicide often deployed in ways which bolster a particular view of gender relations in $21^{\text {st }}$ Century Britain.

Our analysis suggests that understanding male suicide as part of a "crisis of masculinity" tends to reify problematic constructions of gender. While this tendency emerges most starkly in Poole's conservative narrative, it is also reflected in the (more) progressive accounts of Abbott and Powell. This is partly a result of the construction of the problem of suicide as 
being gendered in terms of a binary: between men (who die by suicide), and women (who do not) (Jaworski 2014). In reaffirming this apparent dichotomy, gender more broadly is reaffirmed as essentialised difference between men and women. This is evidenced in the cases featuring increasingly circular and panicky proclamations that we are "not trying to get men to be like women", even where it is acknowledged that the content of masculinity might need to alter.

Overall, there are two important effects of framing male suicide as part of a "crisis of masculinity" across all three accounts analysed. Firstly, suicide is reaffirmed as a distinctively male concern, a male problem. Secondly, the idea of a "crisis" which must be addressed bolsters the notion that "men have problems", and that suicide is an extreme example of men being the new "gender victims". This framing renders invisible high levels of distress experienced by, and the costs of masculinity for, women. Ultimately, positioning male suicide in terms of "masculinity-crisis" buys into, at best, postfeminist, and at worst, anti-feminist, narratives of gender equality as already (more than) achieved for women.

Alongside the problematic politicised effects of these narratives, the simplified treatment of gender as binary inherent to "crisis" framings of gender issues, means that prevention efforts are likely to ignore important intersectional aspects of gender identity. The social structures influencing (completed) suicide amongst poorer men and young gay men for example are obscured in framing the issues as about "men versus women" (McDermott \& Roen, 2016). Whilst there is some recognition in the cases that masculinity norms need to change, there is little engagement with binary notions of gender. Conservative accounts paradoxically seek to bolster traditional notions of masculinity which both maintain men's overall privilege and simultaneously have damaging effects for men, especially those less privileged. Recent analysis has suggested that there are significant cross-national variations in the gap between male and female suicide rates, and that these may be related to societal gender norms (Reeves 
\& Stuckler, 2016). Reeves and Stuckler found smaller gaps between male and female suicide rates (mostly via relatively lower male suicide rates) correlated with more egalitarian gender norms at a national level. This finding is significant for wider debates about the role of masculinity/ies in shaping male suicide rates, serving to unsettle conservative arguments regarding the impact of changing gender norms on male mental health.

Progressive crisis accounts emphasise the need to alter dominant constructions of gender to offset the worst effects of "traditional" masculinity. However, there is less recognition that it is the category of "masculinity" itself and its implicit contrast with "femininity" that is problematic, not just the form of current dominant masculinity models. This ambivalence towards masculinity - in need of change but also desirable in some different manifestation is a tension which constrains the efforts of groups such as CALM and is unlikely to bring about significant social change. This is evident in some suicide prevention campaigns aimed at men which tend, overall, to reassert ideals of masculinity which may contribute to male suicide (Chandler, 2012), especially amongst specific categories of men.

In this paper we have presented a theoretically informed analysis of three cases where public discourse has drawn on notions of 'crisis' to explain suicide among men, relating this to broader 'crises of masculinity'. Our analysis is not intended to be generalizable or comprehensive, but rather to provoke further debate and critical examination of the way in which gender politics infuses understandings and responses to suicide in public debate. As such, there are a number of future directions that would be worthy of consideration. Most obviously, given the growing attention that suicide among men is garnering in public life, there is clear scope to examine the gender politics of a wider range of discourse about suicide and self-harm. In particular, future work could examine whether the progressive/conservative crisis narratives identified here are present in other cultural texts, and if so, whether they have the same constraining effects. We have shown how gender politics are a significant part of 
the gendering of suicide. As such, we hope that our analysis will also serve to provoke closer reflection on the gender politics of suicide prevention efforts, as well as contributing to longstanding calls for suicide research in general to engage more critically with gender (Canetto and Sakinofsky, 1997; Jaworski, 2014).

\section{References}

Andriolo, K. R. (1998). Gender and the Cultural Construction of Good and Bad Suicides. Suicide and Life-Threatening Behavior, 28(1), 37-49. doi:10.1111/j.1943-278X.1998.tb00624.x

Blais, M., \& Dupuis-Déri, F. (2012). Masculinism and the Antifeminist Countermovement. Social Movement Studies, 11(1), 21-39.

CALM. (2014). A Crisis in Modern Masculinity: Understanding the Causes of Male Suicide.

Canetto, S. S. (1991). Gender Roles, Suicide Attempts, and Substance Abuse. The Journal of Psychology, 125(6), 605-620.

Canetto, S. S. (2017). Suicide: Why Are Older Men So Vulnerable? Men And Masculinities, 20(1), 49-70.

Canetto, S. S., \& Cleary, A. (2012). Men, masculinities and suicidal behaviour. Social Science \& Medicine, 74(4), 461-465.

Canetto, S. S., \& Sakinofsky, I. (1998). The Gender Paradox in Suicide. Suicide and Life-Threatening Behavior, 28(1), 1-23.

Carver, T. (1996). Gender Is Not a Synonym for Women. Boulder CO: Lynne Rienner.

Chandler, A. (2016). Self-injury, Medicine and Society: Authentic bodies. Basingstoke: Palgrave Macmillan.

Chandler, A. (2012). Exploring the Role of Masculinities in Suicidal Behaviour. In Wyllie, C., Platt,

S., Brownlie, J., Chandler, A., Connolly, S., Evans, R., et al. (2012). Men, Suicide and Society.

London: Samaritans, 111-125

Cleary, A. (2012). Suicidal action, emotional expression, and the performance of masculinities. Social Science \& Medicine, 74, 498-505.

Connell, R. (2012). Gender, health and theory: Conceptualizing the issue, in local and world perspective. Social Science \& Medicine, 74(11), 1675-1683.

Connell, R. W. (2005a). Change among the Gatekeepers: Men, Masculinities, and Gender Equality in the Global Arena. Signs: Journal of Women in Culture and Society, 30(3), 1801-1825.

Connell, R. W. (2005b). Masculinities (2nd ed.). Cambridge: Polity. 
Courtenay, W. H. (2000). Constructions of masculinity and their influence on men's well-being: a theory of gender and health. Social Science \& Medicine, 50(10), 1385-1401.

Creighton, G., \& Oliffe, J. L. (2010). Theorising masculinities and men's health: A brief history with a view to practice. Health Sociology Review, 19(4), 409-418.

de Boise, S. (2014). Cheer up emo kid: rethinking the 'crisis of masculinity' in emo. Popular Music, $33(2), 225-242$.

Douglas, J. (1967). The Social Meanings of Suicide. Princeton: Princeton University Press.

Durkheim, E. (1952). Suicide: A Study in Sociology. London: Routledge \& Kegan Paul.

Faludi, S. (1991). Backlash: The undeclared war against women. New York: Random House.

Griffin, C. (2000). Discourses of Crisis and Loss: Analysing the 'Boys' Underachievement' Debate. Journal of Youth Studies, 3(2), 167-188.

Hill, T. D., \& Needham, B. L. (2013). Rethinking gender and mental health: A critical analysis of three propositions. Social Science \& Medicine, 92, 83-91.

Jaworski, K. (2003). Suicide and gender: Reading suicide through Butler's notion of performativity. Journal of Australian Studies, 27(76), 137-146.

Jaworski, K. (2014). The Gender of Suicide. Aldershot: Ashgate.

Jordan, A. (2016). Conceptualizing Backlash: (UK) Men's Rights Groups, Anti-Feminism, and Postfeminism, Canadian Journal of Women and the Law, 28(1), 18-44.

Jordan, A. (2014). 'Every Father is a Superhero to his Children': The Gendered Politics of the (Real) Fathers 4 Justice Campaign. Political Studies, 62(1), 83-98.

Kimmel, M. (2013). Angry White Men: American Masculinity at the End of an Era. New York: Nation Books.

Mac an Ghaill, M., \& Haywood, C. (2012). Understanding boys': Thinking through boys, masculinity and suicide. Social Science \& Medicine, 74(4), 482-489.

Mallon, S., Galway, K., Hughes, L., Rondón-Sulbarán, J., \& Leavey, G. (2016). An exploration of integrated data on the social dynamics of suicide among women. Sociology of Health \& Illness, 38(4), 662-675.

Marsh, I. (2010). Suicide: Foucault, History and Truth. Cambridge: Cambridge University Press.

McDermott, E., \& Roen, K. (2016). Queer Youth, Suicide and Self-Harm - Troubled Subjects, Troubling Norms. Basingstoke: Palgrave Macmillan.

McDowell, L. (2000). The Trouble with Men? Young People, Gender Transformations and the Crisis of Masculinity. International Journal of Urban and Regional Research, 24(1), 201-209.

McRobbie, A. (2009). The Aftermath of Feminism: Gender, Culture and Social Change. London: Sage.

Messner, M. A. (2000). Politics of Masculinities: Men in movements. Thousand Oaks: Sage.

Mirowsky, J., \& Ross, C. E. (2003). Social causes of psychological distress (2nd ed.). New York: Walter de Gruyter Inc. 
Möller-Leimkühler, A. M. (2003). The gender gap in suicide and premature death or: why are men so vulnerable? European Archives of Psychiatry and Clinical Neuroscience, 253(1), 1-8.

Oliffe, J. L., Creighton, G., Robertson, S., Broom, A., Jenkins, E. K., Ogrodniczuk, J. S., \& Ferlatte, O. (2016). Injury, Interiority, and Isolation in Men's Suicidality. American Journal of Men's Health. 11(4), 888-899.

Payne, S., Swami, V., \& Stanistreet, D. L. (2008). The social construction of gender and its influence on suicide: a review of the literature. Journal of Men's Health, 5(1), 23-35.

Powell, J. (2014). Is Male A Dirty Word? Retrieved from http://www.huffingtonpost.co.uk/janepowell/mens-issues-feminism_b_4902148.html

Powell, J. (2016). 76\% of suicides are male - WHY? Retrieved from http://www.huffingtonpost.co.uk/jane-powell/world-suicide-preventionday_b_11947706.html

Reeves, A., \& Stuckler, D. (2016). Suicidality, Economic Shocks, and Egalitarian Gender Norms. European Sociological Review, 32(1), 39-53. doi:10.1093/esr/jcv084

Roberts, S. (2014). Introduction: Masculinities in Crisis? Opening the Debate. In S. Roberts (Ed.), Debating Modern Masculinities: Change, Continuity, Crisis? Basingstoke: Palgrave Macmillan.

Scourfield, J. (2005). Suicidal Masculinities. Sociological Research Online, 10(2).

Scourfield, J., Fincham, B., Langer, S., \& Shiner, M. (2012). Sociological autopsy: An integrated approach to the study of suicide in men. Social Science \& Medicine, 74, 466-473.

Scowcroft, E. (2017). Suicide statistics report 2017. Samaritans

Squires, J. (1999). Gender in Political Theory. Cambridge: Polity.

Timmermans, S. (2005). Suicide Determination and the Professional Authority of Medical Examiners. American Sociological Review, 70(2), 311-333.

Welford, J., \& Powell, J. (2014). A Crisis in Modern Masculinity: Understanding the Causes of Male Suicide. London: CALM

White, J., Marsh, I., Kral, M. J., \& Morris, J. (Eds.). (2016). Critical Suicidology: Transforming Suicide Research and Prevention for the 21st Century. Vancouver: UBC Press.

Whitehead, S. M. (2002). Men and Masculinities: Key Themes and New Directions. Cambridge: Polity.

Wyllie, C., Platt, S., Brownlie, J., Chandler, A., Connolly, S., Evans, R., Scourfield, J. (2012). Men, Suicide and Society. London: Samaritans 
